Polymer Journal, Vol. 39, No. 10, pp. 1071-1077 (2007)

(C)2007 The Society of Polymer Science, Japan

\title{
A Supramolecular Chiroptical Switch Based on Chitosan and Anionic Porphyrin Complex Film
}

\author{
Bo LIAO, ${ }^{1,2}$ Ruigang LIU, ${ }^{1}$ and Yong HUANG ${ }^{1,3, \dagger}$ \\ ${ }^{1}$ State Key Laboratory of Polymer Physics and Chemistry, Joint Laboratory of Polymer Science and Materials, \\ Beijing National Lab of Molecular Science, Institute of Chemistry, Chinese Academy of Science, Beijing, 100080, China \\ ${ }^{2}$ Graduate School, Chinese Academy of Sciences, Beijing 100039, China \\ ${ }^{3}$ Laboratory of Cellulose and Lignocellulosics Chemistry, Guangzhou Institute of Chemistry, \\ Chinese Academy of Sciences, Guangzhou 510650, China
}

(Received May 8, 2007; Accepted July 17, 2007; Published September 4, 2007)

\begin{abstract}
A supramolecular chiroptical switch based on chitosan and tetrakis (4-sulfonatophenyl) porphine (TPPS) complex films was prepared. The reversible changes of the chirality of the complex films were studied by UV-vis and circular dichroism (CD) spectra. It was found that the chirality of the complex films can be wiped off by being exposed to $\mathrm{NH}_{3}$ gas and subsequently recovered by being exposed to moist $\mathrm{HCl}$ gas. The complex film is stable and can stand at least 20 cycles of the switching to $\mathrm{NH}_{3}$ and $\mathrm{HCl}$ gases. There is no change in the above properties after the complex films were store in the air at room temperature. [doi:10.1295/polymj.PJ2007036]

KEY WORDS Supramolecular Chirality / Chitosan / Chiroptical Switch / Porphyrin /
\end{abstract}

Chirality is an attractive issue in chemistry, biology, material science etc. and has been studied extensively. ${ }^{1-4}$ The chiral switch, which shows the reversible change in chirality with an external stimulation, is particularly attractive due to the potential applications in data storage and sensor systems. ${ }^{5-9}$ Many chiral optical switches have been proposed, which are based on photochemically induced interconversions, ${ }^{10,11}$ photochemically induced changes in liquid crystals, ${ }^{12,13}$ stereoisomers of chiral photoresponsive molecules and chiral supramolecular systems, ${ }^{14,15}$ etc. The most attractive one in this filed is the chiral optical supramolecular switch because it is easily controlled. ${ }^{16-19}$ Tetrakis(4-sulfonatophenyl)porphine (TPPS, Figure 1) is a well investigated dye. It has two negative charges and forms stable $\mathrm{J}$ - and $\mathrm{H}$-aggregates depending on the $\mathrm{pH}$ and ionic strength in the system. The TPPS $\mathrm{J}$ - and $\mathrm{H}$-aggregates shows the property of induced chirality in many systems, such as multilayer and Langmuir-Schaefer (L-S) films prepared from chiral and achiral molecules, ${ }^{20-23}$ the solutions containing polylutamic acid, polylysine, cationic porphyrin etc., ${ }^{24-30}$ and even by mechanical stirring in solutions. ${ }^{31}$ However, there is no report about the reversible chirality of TPPS aggregates in film.

Chitosan, a chiral biopolymer, is used widely in many fields, e.g. biomedical ${ }^{32-34}$ and chemical materials, ${ }^{35}$ textiles, ${ }^{36}$ pharmaceutics, ${ }^{37,38}$ etc. Chitosan is a cationic polyelectrolyte and can interact with the anionic TPPS. More recently, Synytsya et al..$^{39}$ studied the interaction of TPPS with chitosan in aqueous solutions at different $\mathrm{pH}$ value. The results confirmed that the formation of optically active species of TPPS in the presence of chitosan and the $\mathrm{J}$ - and $\mathrm{H}$-aggregates depended on $\mathrm{pH}$ value and chitosan concentration. However, no work had been reported on the interactions between TPPS and chitosan on chitosan film.

In this paper, the reversible change in chirality of chitosan/TPPS complex films when they are alternatively exposed in moist $\mathrm{HCl}$ and $\mathrm{NH}_{3}$ gases was studied. The morphology of the complex films and the interaction between chitosan and TPPS were discussed.

\section{EXPERIMENTAL}

Water-soluble anionic porphyrin TPPS was purchased from Dojindo Laboratories. Chitosan $\left(M_{\mathrm{n}}=\right.$ $100 \mathrm{Kda}$, the degree of deacetylation was $91 \mathrm{~mol} \%$ ) was received from Professor Yanming Dong's laboratory, Xiamen University.

TPPS was dissolved in deionized water and then the $\mathrm{pH}$ value of the solution was adjusted to 6.6 by adding $\mathrm{NaOH}$. The concentration of TPPS in the final solution was $20 \mu \mathrm{M}$. Chitosan was dissolved in $0.5 \%$ acetic acid solution with a concentration of 10 $\mathrm{mg} / \mathrm{mL}$.

Chitosan film was prepared with the chitosan solution by spin-coating and air dried on clean quartz. The film was neutralized by exposed in $\mathrm{NH}_{3}$ gas and then immersed in the TPPS stock solution. Chitosan/TPPS complex film was obtained after the film was removed from the TPPS solution and dried A red complex film about $1 \mu \mathrm{m}$ in thickness was obtained. The TPPS film

${ }^{\dagger}$ To whom correspondence should be addressed (Tel: 0086-10-82618573, Fax: 0086-10-62559373, E-mail: yhuang@ cashq.ac.cn). 


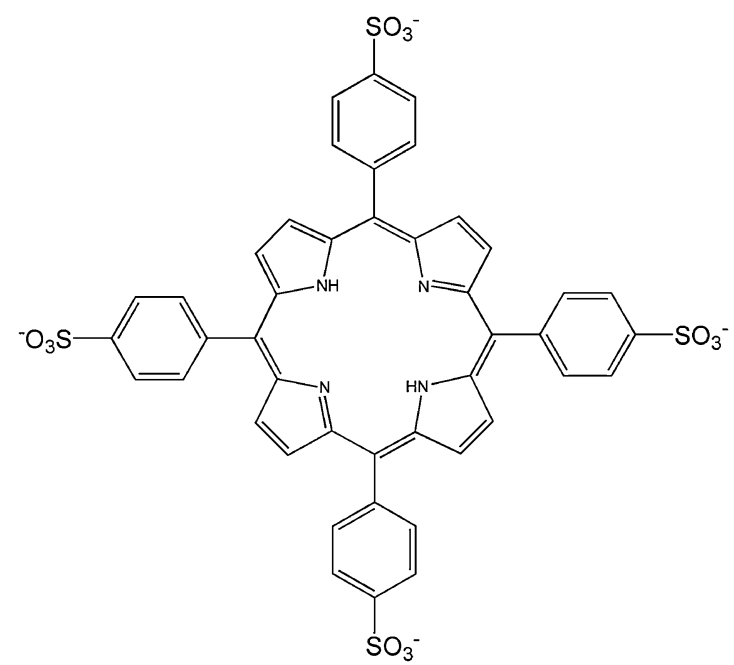

Figure 1. Chemical structure of non-protonated TPPS.

was prepared by dropping with $50 \mu \mathrm{L}$ TPPS solution on a piece of clean quartz $\left(C_{\text {TPPS }}=0.2 \mathrm{mM}, \mathrm{pH}=\right.$ 4.0) and air dried. The chirality switch was achieved by a sequence exposing the chitosan/TPPS complex films in moist $\mathrm{HCl}$ and $\mathrm{NH}_{3}$ gas for 15 seconds and 10 seconds, respectively. The moist $\mathrm{HCl}$ gas is composed of water vapor from $50{ }^{\circ} \mathrm{C}$ water and $\mathrm{HCl}$ gas.

UV-vis spectra of the complex film were recorded on a Vrian model UV-530 spectrophotometer and circular dichroism (CD) spectra were recorded by a CD spectrophotometer (JASCO, model J-810), the recording range is $200 \mathrm{~nm}-800 \mathrm{~nm}$. During CD spectral recoding, the complex film was placed perpendicular to the light path and rotated within the film plane, by which the polarization-dependent reflection was avoided and the possible angle dependence of the CD signals was also eliminated.

Atomic force microscopy (AFM) images were collected with a Nanoscope III multimode atomic force microscope (Veeco Metrology Group) in the tapping mode. FT/IR spectra of the films depoisted on $\mathrm{CaF}_{2}$ were recorded by a Bruker-Equinox 55 FT/IR spectrometer.

\section{RESULTS AND DISCUSSION}

Figure 2a shows the UV-vis spectrum of the aqueous TPPS solution at $\mathrm{pH}=6.6$. The strong absorption at $414 \mathrm{~nm}$ and several weak absorptions come from the B-band and Q-bands of the non-protonated TPPS monomer. In this work, the complex films of chitosan/TPPS were prepared by dipping the chitosan film in TPPS solution, in which the anionic porphyrin TPPS absorbed to polycationic chitosan film by electrostatic force. The absorption process was monitored by using UV-vis spectroscopy and the results are shown in Figure $2 b$ as a function of the immersing time. The results show that there are two absorption bands at $410 \mathrm{~nm}$ and $422 \mathrm{~nm}$, which are attributed to the non-protonated TPPS monomer and the B-bands of the TPPS H-aggregate, respectively. However, when a piece of clean quartz without chitosan was immersed the TPPS solution for enough time, there was no any UV-vis absorption signal in the TPPS absorption region after it was removed from the TPPS solution, which indicates that the TPPS can not be absorbed by the clean quartz without chitosan. All of the results indicate that TPPS is absobed just by the chitosan film on the quartz and the $\mathrm{H}$-aggregates are formed when TPPS is absorbed on to the chitosan film. Moreover, the relative intensity of the peaks at $410 \mathrm{~nm}$ and $422 \mathrm{~nm}$ change with the time that the chitosan immersed in the TPPS solution. In details, the intensity of the absorption peak of TPPS H-aggregate at $422 \mathrm{~nm}$ is much higher than that of $410 \mathrm{~nm}$ firstly, while the intensity of the absorption peak at $410 \mathrm{~nm}$ increases much faster than that of $422 \mathrm{~nm}$. Both of the absorption bands saturated at about $60 \mathrm{~min}$. At $\mathrm{pH}$ value of 6.6, part of chitosan amino groups are protonated and the anionic sulphonato groups are shielded by the counter ions, ${ }^{39}$ which leads the aggregation of the non-protonated TPPS monomers to Haggregates. With the increasing of the loading time, the non-protonated TPPS monomer in the film increases, while the chitosan amino groups in the proto-
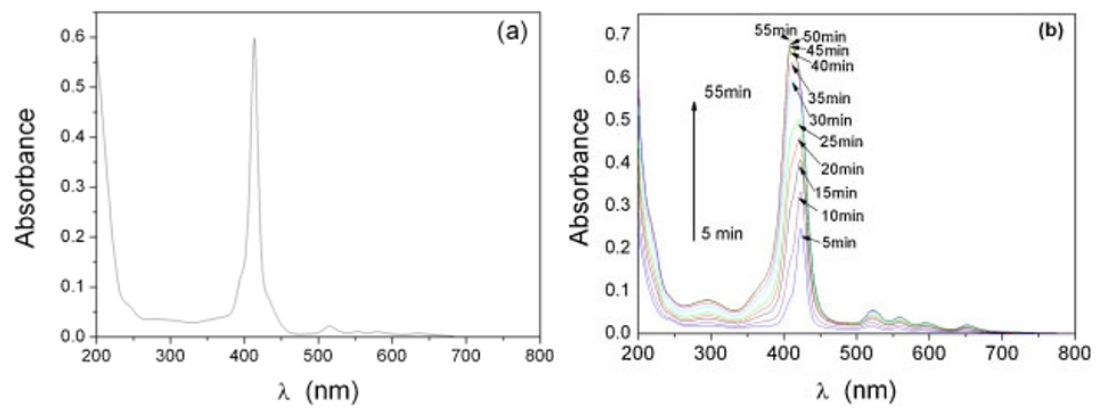

Figure 2. The UV-vis absorbance spectra of (a) TPPS solution and (b) the chitosan complex film after being immersed in the TPPS solution for different time. 

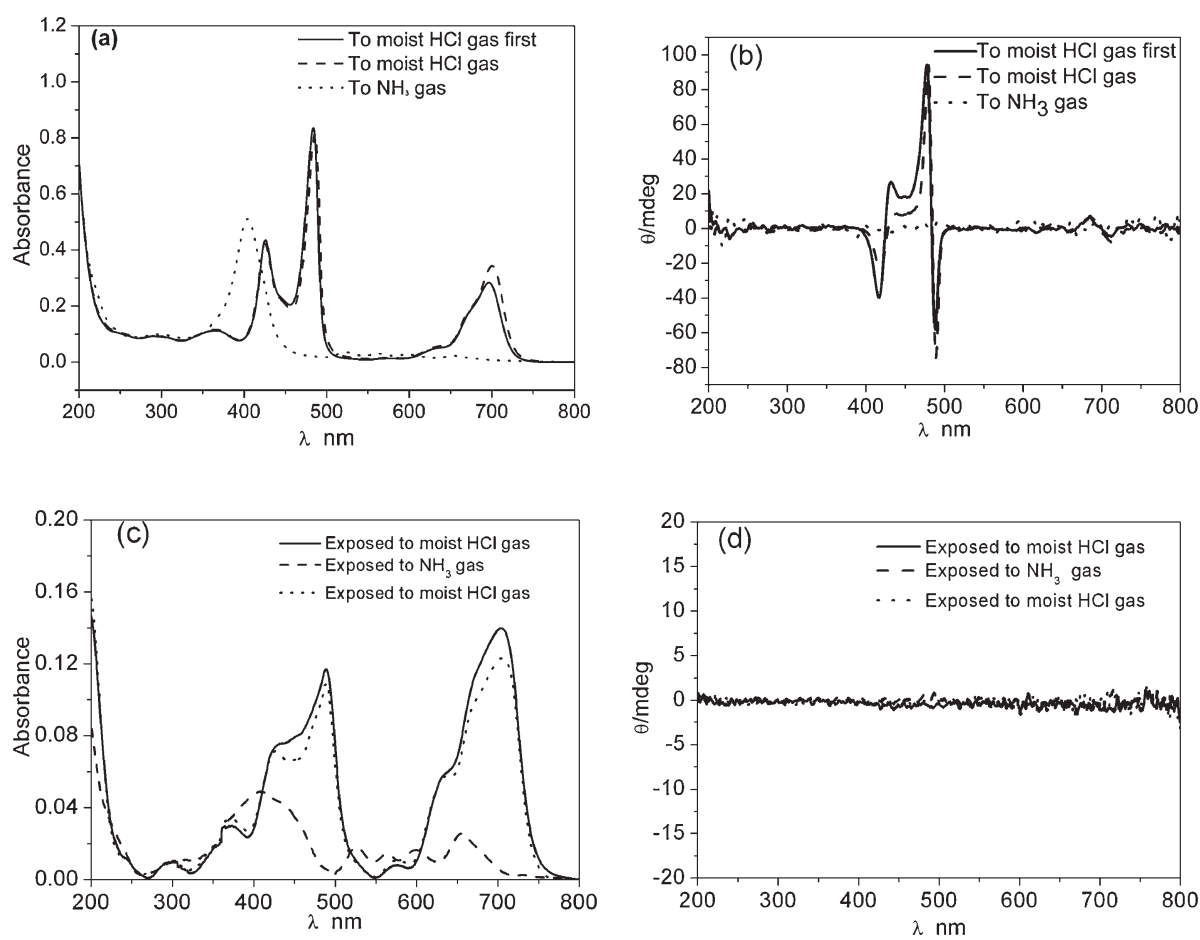

Figure 3. UV-vis (a) and CD (b) spectra of the chitosan/TPPS complex film, and UV-vis (c) and CD (d) spectra of TPPS film on clean quartz without chitosan, when being exposed to $\mathrm{NH}_{3}$ gas and to mosit $\mathrm{HCl}$ gas.

nated form are not changed, which results in the absorbance of the non-protonated monomers is stronger than that of the $\mathrm{H}$-aggregates in the film in the end. The saturated film is dark red in color and no CD signal can be observed, which indicates that there is no induced chirality in the prepared complex film. Similar results were observed in the chitosan/TPPS solutions in the $\mathrm{pH}$ range from 5.6 to $6.8 .{ }^{39}$

When the non-induced chirality as-prepared complex film is exposed in moist $\mathrm{HCl}$ gas for $15 \mathrm{~s}$, the color of complex film is changed into green, and the absorption bands for TPPS B-band of $\mathrm{H}$-aggregates and B-band and Q-band of J-aggregates, at 424, 491 and $707 \mathrm{~nm}$, respectively, appear on the UV-vis spectra (Figure 3a). Simultaneously, the absorption band of TPPS monomers at 410 disappears. CD spectra shows some splitting $\mathrm{CD}$ signals at these absorption bands (Figure 3b). When the film is exposed in $\mathrm{NH}_{3}$ gas, the color of the film is changed from green to rosiness immediately. Meanwhile, the absorption bands at 424,488 , and $704 \mathrm{~nm}$ disappear and a new absorption band at $404 \mathrm{~nm}$, which is attributed to the nonprotonated TPPS single molecules, appears simultaneously (Figure 3a, dash line). The results indicate that the $\mathrm{H}$ - and J-aggregates of the TPPS are disaggregated and turned into non-protonated molecules when the film is exposed in $\mathrm{NH}_{3}$ gas. When the complex film is subsequently exposed in the moist $\mathrm{HCl}$ gas, its color is recovered from rosiness to green immediately and the absorption band of the non-protonated TPPS mole- cules disappears in the UV-vis spectra and the absorption bands of the $\mathrm{H}$ - and $\mathrm{J}$-aggregates are recovered in the UV-vis spectra (Figure 3a, dotted line). The results indicate that the non-protonated TPPS single molecules are re-assembled into $\mathrm{H}$ - and $\mathrm{J}$-aggregates when the complex film is exposed in the moist $\mathrm{HCl}$ gas. Figure $3 b$ shows the CD spectra of the complex film at different stages. There are three CD bands in the CD spectrum of the original complex film (solid line in Figure $3 b$ ). The one centered at $421 \mathrm{~nm}$ with splittig attributes to the TPPS H-aggregates. ${ }^{20}$ The others centered at 484 and $700 \mathrm{~nm}$ come from the Jaggregates. ${ }^{20}$ The results suggest that $\mathrm{H}$ - and J-aggregates show induced chirality on the chitosan film in the presence of the acid atmosphere. Moreover, the $\mathrm{H}$ - and J-aggregates show D-type and L-type induced chirality respectively. ${ }^{39}$ After the complex film is exposed in $\mathrm{NH}_{3}$ gas, no $\mathrm{CD}$ signals can be observed in the range of TPPS absorption (Figure 3b, dash line). While when the film is subsequently exposed in moist $\mathrm{HCl}$ gas, the $\mathrm{CD}$ signals in the range of $\mathrm{H}-$ and $\mathrm{J}$ aggregates absorption of the TPPS reappear and are similar to those of the original film (Figure $3 b$, dotted line). In the same way, the UV-vis and CD spectra changes of TPPS film on the clean quartz without chitosan when it is exposed to the moist $\mathrm{HCl}$ or $\mathrm{NH}_{3}$ gas were investigated. Though TPPS can be assembled into $\mathrm{H}$ - and $\mathrm{J}$-aggregates when it is exposed to the moist $\mathrm{HCl}$ gas (as shown in Figure 3c), no any $\mathrm{CD}$ signals can be observed in the absorption re- 


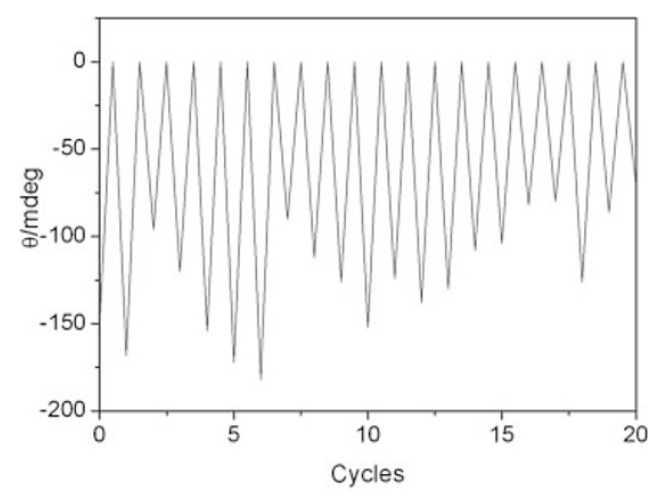

Figure 4. The CD couplet amplitude of TPPS J-aggregates at the Soret band changes with cycles.

gion of TPPS (as shown in Figure 3d). All of the results indicate that the chirality of TPPS aggregates in the complex film should come from the inducement of chitosan. At the same time, it is found that the reversibility of the $\mathrm{CD}$ signal changes of the complex film can be repeated for many times, and it is clarified by the CD couplet amplitude of the TPPS J-aggregates at the B-band as a function of cycles in Figure 4. It is showed in Figure 4 that the complex film stands at lest 20 cycles of the change between chirality and achirality mentioned above without obviously decay in the $\mathrm{CD}$ intensity. Moreover, after being stored in air at room temperature for more than one month, the $\mathrm{CD}$ signals of the complex film can still observed without obvious change in the UV-vis spectra and CD signals. Meanwhile, the chirality of the complex film is still sensitive to $\mathrm{NH}_{3}$ gas and moist $\mathrm{HCl}$ gas as the original one, and the reversible change between chirality and achirality can be still repeated many cycles. It should be noted that $\mathrm{NH}_{4} \mathrm{Cl}$ produced in the experimental process, which is increased with the increament of the cycles. However, no obvious weakening of the $\mathrm{CD}$ signals was observed during the 20 cycles as shown in Figure 4. Therefore, it is reasonable to consider that the production of $\mathrm{NH}_{4} \mathrm{Cl}$ has no or only a trivial influence on $\mathrm{CD}$ signals.

It is known that the CD signal can be affected by the linear dichromism (LD) during CD measurement. ${ }^{40-42}$ In this work, the influence of the LD was eliminated by averaging at different angles with the similar procedure reported in literatures. ${ }^{23,41,42}$ It has been found that the average of the CD spectra at eight angles $\left(0^{\circ}, 45^{\circ}, 90^{\circ}, 135^{\circ}, 180^{\circ}, 225^{\circ}, 270^{\circ}, 315^{\circ}\right.$, and $360^{\circ}$ ) results similar $\mathrm{CD}$ spectra as those in a rotating manner (Figure 5). The CD spectra reported in this paper are measured by rotating the film during the measurement.

The above discussions indicate that the complex film shows chirality when it is exposed to the moist $\mathrm{HCl}$ gas and TPPS is in its $\mathrm{H}$ - and $\mathrm{J}$-aggregates states.

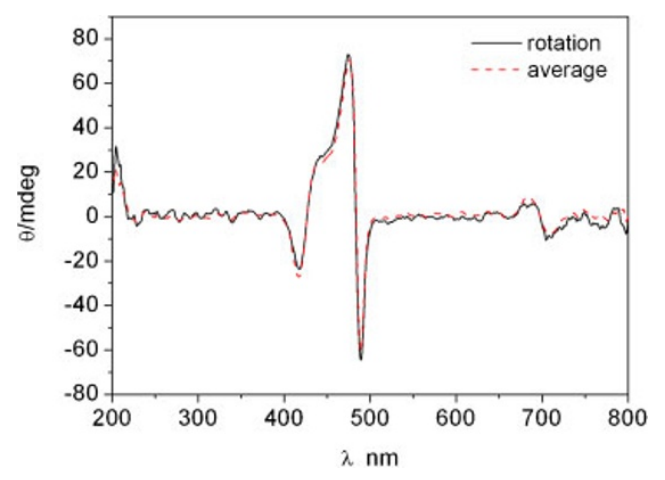

Figure 5. Comparison between the CD spectra of chtiosan/ TPPS complex films obtained by averaging the CD spectrum in eight different rotation angles $(0,45,90,135,180,225,270$, 315 , and $360^{\circ}$ ) and that obtained by continuous rotation.

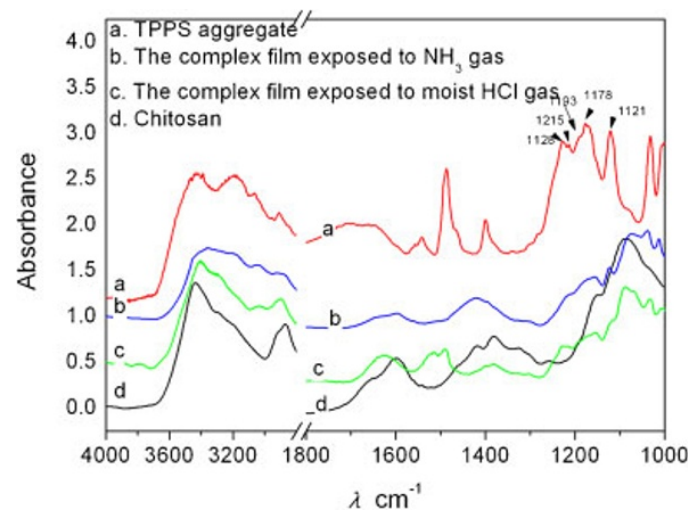

Figure 6. FT/IR spectra of TPPS aggregate, the chitosan, the chitosan/TPPS complex film exposed to moist $\mathrm{HCl}$ and subsequently $\mathrm{NH}_{3}$ gas, respectively.

In this case, both chitosan and TPPS molecules are protonated. Therefore, it is reasonable that the chirality of the complex comes from the interaction between TPPS and chitosan, which can be confirmed by FT/IR (Figure 6). In the FT/IR spectrum of the TPPS aggregates, the bands at 1230, 1215, 1193, 1178 and 1121 $\mathrm{cm}^{-1}$ are all attributed to $-\mathrm{SO}^{3-}$ groups stretching vibration. ${ }^{43,44}$ In the FT/IR spectrum of the TPPS/ chitosan complex film that is exposed to the moist $\mathrm{HCl}$ gas, the characteristic band of chitosan corresponding to the $\mathrm{NH}_{2}$ scissoring vibration of primary amino group at $1600 \mathrm{~cm}^{-1}$ is absent. At the same time, the band at $3600-2800 \mathrm{~cm}^{-1}$, which is attributed to stretching vibration of primary amino group, shifts to the lower wavelength. Simultaneously, the intensity of the absorption bands of the - $\mathrm{SO}^{3-}$ groups stretching of the TPPS aggregates at 1215 and $1193 \mathrm{~cm}^{-1}$ decrease and the absorption bands of the $-\mathrm{SO}^{3-}$ groups of TPPS aggregates at in the chitosan/TPPS complex film at $1178 \mathrm{~cm}^{-1}, 1121 \mathrm{~cm}^{-1}$ shift to $1171 \mathrm{~cm}^{-1}$ and $1116 \mathrm{~cm}^{-1}$, respectively. The results indicate there are interactions between - $\mathrm{SO}^{3-}$ groups of the TPPS aggregates and amino groups of chitosan. After the complex 
film is exposed to the $\mathrm{NH}_{3}$ gas, the typical absorption peak of the chitosan amino group at $1600 \mathrm{~cm}^{-1}$ reappears and the absorption band of the $-\mathrm{SO}^{3-}$ groups of the TPPS at 1230 disappears, the band at $1121 \mathrm{~cm}^{-1}$ shift to $1125 \mathrm{~cm}^{-1}$, which suggests that the TPPS molecules and the chitosan are deprotonated and the ionic interaction between the TPPS and the chitosan disappears.

The TPPS aggregates in the chitosan complex film show splitting CD signals in the absorption regions. The split CD signals come from excited coupling and suggest that the TPPS aggregates are CD activity. It is well known that TPPS aggregates are easily induced to show $\mathrm{CD}$ activity by achiral molecules or even by mechanical stirring. ${ }^{31}$ The chirality of TPPS aggregates is normally attributed to the helical formation of the TPPS aggregates due to the broken of the mirror-symmetry of the diprotonated porphyrins in the TPPS aggregates or the formation of a $90^{\circ}$ fold of the TPPS aggregates. ${ }^{31}$ It has been reported that in tryptophan chiral L- or D-isomers solutions, the chirality of the TPPS aggregates always follows the chiral molecules and the TPPS aggregates form Lor D-helix respectively. ${ }^{45}$ Moreover, the chirality of the TPPS J-aggregates in the complex L- or D-Trp multiplayer films formed via ex situ also follows the chirality of films. ${ }^{22}$ All the reported results indicate that the presence of the chiral molecules promotes the broken of the mirror-symmetry of diprotonated porphyrins in the TPPS aggregates, which results in the induced chirality of the TPPS aggregates. More recently, the chirality of the TPPS aggregates in chitosan solutions has been studied. ${ }^{39}$ It has been found that the distance of the neighbored amino groups in chitosan is similar to that of the neighbor non-bonded sulphonato groups in the TPPS aggregates if the porphyrin molecules are in half-overlapped. Therefore, the optically active twisted structure of the TPPS aggregates comes from the helical distortion of the TPPS aggregates induced by the chiral chitosan molecules. ${ }^{39}$ The splitting CD signals of TPPS aggregates may come from either the adjacent aggregates that are arranged along the chitosan helix or the helix of the aggregate itself. It has been reported that L- and D-helix structure of TPPS aggregates can be formed in chitosan solution. ${ }^{39}$ In this work, the CD activity of the TPPS aggregates in the complex film should be similar to that in the solution of chitosan and comes from the helix of the TPPS aggregate itself. ${ }^{39}$ When the complex film is exposed to the moist $\mathrm{HCl}$ gas, the amine groups on the backbone of the chitosan molecules and TPPS molecules are protonated and the TPPS molecules self-assemble into $\mathrm{H}$ - and J-aggregates simultaneously with helix due to the promoting of the chiral chitosan (as illustrated in Figure 7a).

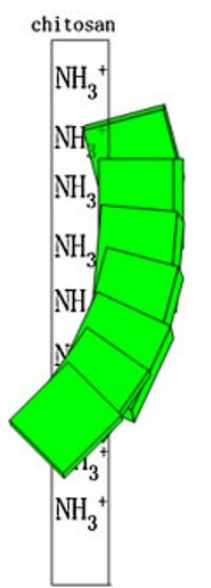

(a) (b)
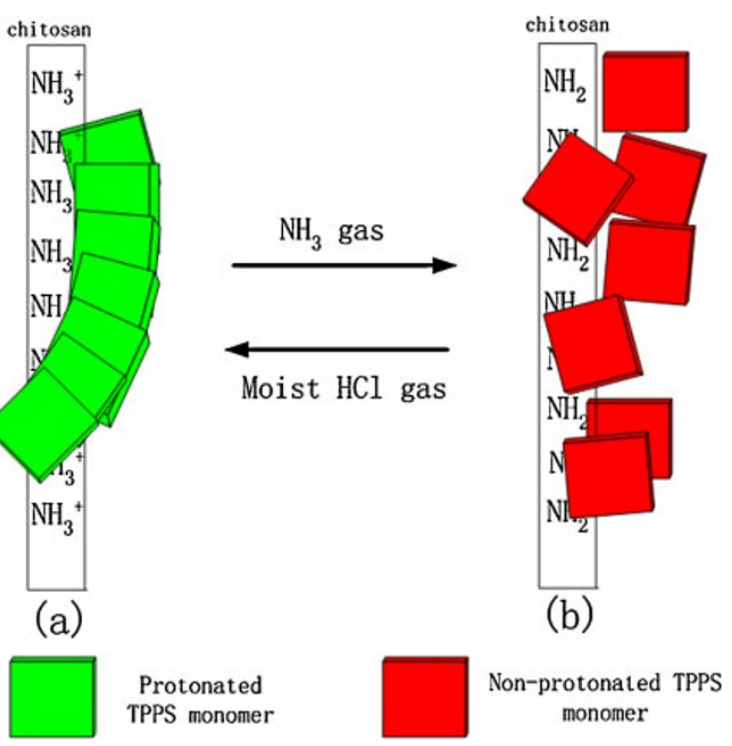

Figure 7. Illustration of aggregation (a) and disaggregation (b) of TPPS in the chitosan complex film.

When the complex film is exposed to the $\mathrm{NH}_{3}$ gas, the amine groups on the backbone of the chitosan chains and TPPS molecules are deprotonated and the TPPS molecules are disaggregated, which results in the loss of the chirality of the TPPS aggregates (as illustrated in Figure 7b).

The morphology of the complex films was investigated by AFM and the results are shown in Figure 8. The results show that the as prepared chitosan film is smooth and without any special structures (Figure 8a). After the chitosan film is exposed to moist $\mathrm{HCl}$ gas, the chitosan molecules aggregate to a worm-like morphology (Figure 8b). When the chitosan/TPPS complex film is exposed to the moist $\mathrm{HCl}$ gas, a granular structure tightly packed on the surface of the file can be observed (Figure 8c), which suggests that the TPPS molecules are aggregated in the chitosan film and form short-range ordered aggregates. When the complex film is exposed to the $\mathrm{NH}_{3}$ gas, it can be found that the granular structure disappeared (Figure 8d), which indicates the disaggregation of the TPPS aggregates occurs at this time. Therefore, it can be concluded that the CD activity should come from the granular structure in the chitosan/TPPS complex film. However, it is a pity that more details of the morphology, such as the helix structure, of the TPPS aggregates can not be observed by AFM.

The chiral switches based on dye-intercalated DNA film ${ }^{5}$ and L-S film ${ }^{8}$ have also been reported by liu's group. In the dye-intercalated DNA film, the chirality can be wiped off by the $\mathrm{HCl}$ gas and be recovered by the $\mathrm{NH}_{3}$ gas and water vapor due to the protonation and deprotonation of the dye TMPyP respectively. But the intensity of the CD signals may be reduced after 10 cycles. In our case, the reversible change be- 


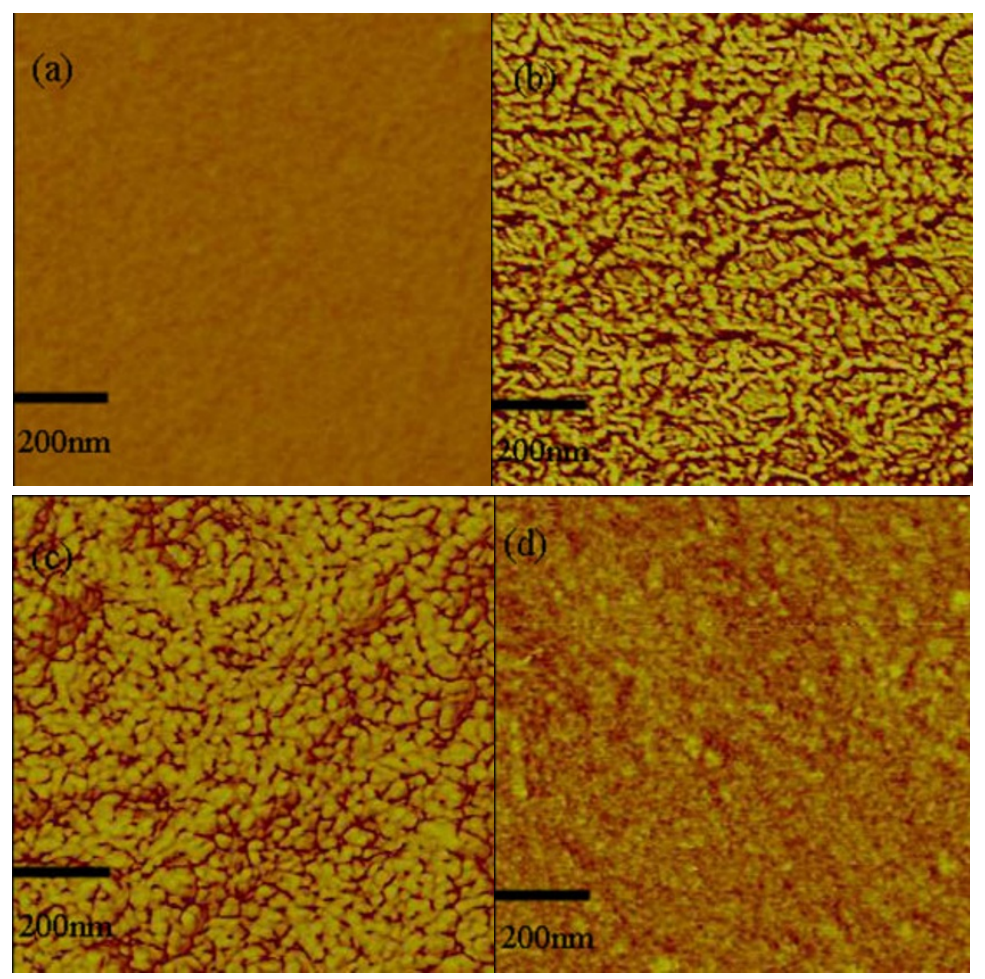

Figure 8. AFM images of (a) the chitosan film, (b) the chitosan film exposed to moist $\mathrm{HCl}$ gas, (c) chitosan/TPPS complex film exposed to the moist $\mathrm{HCl}$ gas, (d) chitosan/TPPS complex film exposed to the $\mathrm{NH}_{3}$ gas. Images size: $1 \mu \mathrm{m} \times 1 \mu \mathrm{m}$.

tween the chirality and achirality in the chitosan/ TPPS complex films can be repeated many cycles even after the complex film is stored in air for more than one month, which indicates that the obtained chitosan/TPPS complex film is stable the reversible change of the chirality and can be practical used as a chiroptical switch.

\section{CONCLUSIONS}

Chitosan/TPPS complex films are prepared and the film shows supramolecular chirality induced by chitosan to the TPPS aggregates. The suparmolecular chirality of the complex films is sensitive to the $\mathrm{NH}_{3}$ and moist $\mathrm{HCl}$ gases and is reversible when it is alternatively exposed in the $\mathrm{NH}_{3}$ and the moist $\mathrm{HCl}$ gases. The complex film is stable and can stand at least 20 cycles of the changes between the chirality and achirality in the $\mathrm{NH}_{3}$ and the $\mathrm{HCl}$ gases. The storage of complex film at room temperature in the air for more than month has no obvious influence on its chiroptical switch properties.

\section{REFERENCES}

1. A. K. M. F. Azam, M. Kamigaito, M. Tsuji, and Y. Okamoto, Polym. J., 38, 1173 (2006).

2. K. Nozaki, Polym. J., 37, 871 (2005).

3. Y. Inai and H. Komori, Biomacromolecules, 5, 1231 (2004).
4. M. Wei, Q. Yuan, D. G. Evans, Z. Wang, and X. Duan, J. Mater. Chem., 15, 1197 (2005).

5. S. G. Jiang and M. H. Liu, Chem. Mater., 16, 3985 (2004).

6. B. L. Feringa, N. P. M. Huck, and A. M. Schoevaars, $A d v$. Mater., 8, 681 (1996).

7. B. L. Feringa, N. P. M. Huck, and H. A. van Doren, J. Am. Chem. Soc., 117, 9929 (1995).

8. P. Z. Guo, L. Zhang, and M. H. Liu, Adv. Mater., 18, 177 (2006).

9. A. P. de Silva, H. Q. N. Gunaratne, T. Gunnlaugsson, A. J. M. Huxley, C. P. McCoy, J. T. Rademacher, and T. E. Rice, Chem. Rev., 97, 1515 (1997).

10. N. Tamai, T. Saika, T. Shimidzu, and M. Irie, J. Phys. Chem., 100, 4689 (1996).

11. J. J. D. De Jong, L. N. Lucas, R. M. Kellogg, J. H. van Esch, and B. L. Feringa, Science, 304, 278 (2004).

12. S. Kurihara, A. Sakamoto, and T. Nonaka, Macromolecules, 31, 4648 (1998).

13. A. Shishido, O. Tsutsumi, A. Kanazawa, T. Shiono, T. Ikeda, and N. Tamai, J. Am. Chem. Soc., 119, 7791 (1997).

14. E. Yashima, K. Maeda, and T. Nishimura, Chem. Eur. J., 10, 42 (2004).

15. E. Yashima, T. Matsushima, and Y. Okamoto, J. Am. Chem. Soc., 117, 596 (1995).

16. J. W. Canary, A. E. Holmes, and J. Liu, Enantiomer, 6, 181 (2001).

17. S. Allenmark, Chirality, 15, 409 (2003).

18. T. Ishi-i, M. Crego-Calama, P. Timmerman, D. N. Reinhoudt, and S. Shinkai, J. Am. Chem. Soc., 124, 14631 (2002).

19. M. Oda, H.-G. Nothofer, G. Lieser, U. Scherf, S. C. J. 
Meskers, and D. Neher, Adv. Mater., 12, 362 (2000).

20. S. G. Jiang and M. H. Liu, J. Phys. Chem. B, 108, 2880 (2004).

21. X. D. Zhai, L. Zhang, and M. H. Liu, J. Phys. Chem. B, 108, 7180 (2004).

22. L. Zhang, J. Yuan, and M. H. Liu, J. Phys. Chem. B, 107, 12768 (2003).

23. L. Zhang, Q. Lu, and M. H. Liu, J. Phys. Chem. B, 107, 2565 (2003).

24. R. Purrello, L. Monsu' Scolaro, E. Bellacchio, S. Gurrieri, and A. Romeo, Inorg. Chem., 37, 3647 (1998).

25. R. Purrello, E. Bellacchio, S. Gurrieri, R. Lauceri, A. Raudino, L. M. Scolaro, and A. M. Santoro, J. Phys. Chem. $B, \mathbf{1 0 2}, 8852$ (1998).

26. S. Geremia, L. Di Costanzo, G. Nardin, L. Randaccio, R. Purrello, D. Sciotto, R. Lauceri, and F. Pichierri, Inorg. Chem., 43, 7579 (2004).

27. R. Lauceri, S. Gurrieri, E. Bellacchio, A. Contino, L. Monsu'scolaro, A. Romeo, A. Toscano, and R. Purrello, Supramol. Chem., 12, 193 (2000).

28. E. Bellacchio, R. Lauceri, S. Gurrieri, L. M. Scolaro, A. Romeo, and R. Purrello, J. Am. Chem. Soc., 120, 12353 (1998).

29. M. De Napoli, S. Nardis, R. Paolesse, M. G. H. Vicente, R. Lauceri, and R. Purrello, J. Am. Chem. Soc., 126, 5934 (2004).

30. R. Lauceri, A. Raudino, L. M. Scolaro, N. Micali, and R. Purrello, J. Am. Chem. Soc., 124, 894 (2002).

31. R. Rubires, J. Farrera, and J. M. Ribo, Chem. Eur. J., 7, 436 (2001).
32. S. Rikimaru, Y. Wakabayashi, M. Nomizu, and N. Nishi, Polym. J., 35, 255 (2003).

33. J. H. Kim, S. J. Sim, D. H. Lee, D. J. Kim, Y. K. Lee, D. J. Chung, and J.-H. Kim, Polym. J., 36, 943 (2004).

34. E. Renbutsu, M. Hirose, Y. Omura, F. Nakatsubo, Y. Okamura, Y. Okamoto, H. Saimoto, Y. Shigemasa, and S. Minami, Biomacromolecules, 6, 2385 (2005).

35. A. Yanagi, H. Otsuka, and A. Takahara, Polym. J., 37, 939 (2005).

36. S. H. Lim and S. M. Hudson, J. Macromol. Sci. Polym. Rev., C43, 223 (2003).

37. H. M. Yi, L. Q. Wu, W. E. Bentley, R. Ghodssi, G. W. Rubloff, J. N. Culver, and G. F. Payne, Biomacromolecules, 6, 2881 (2005).

38. J. Berger, M. Reist, J. M. Mayer, O. Felt, N. A. Peppas, and R. Gurny, Eur. J. Pharm. Biopharm., 57, 19 (2004).

39. A. Synytsya, P. Blafkova, K. Volka, et al., Spectrochim Acta, Part A, 66, 225 (2007).

40. B. Norden, J. Phys. Chem., 81, 151 (1977).

41. F. D. Saeva and G. R. Olin, J. Am. Chem. Soc., 99, 4848 (1977).

42. C. Spitz, S. Dähne, A. Ouart, and H.-W. Abraham, J. Phys. Chem. B, 104, 8664 (2000).

43. Y. H. Zhang, D. M. Chen, T. J. He, and F. C. Liu, Spectrochim Acta, Part A, 59, 87 (2003).

44. J. M. Ribo, R. Rubires, Z. El-Hachemi, J.-A. Farrera, L. Campos, G. L. Pakhomov, and M. Vendrell, Mater. Sci. Eng., C, 11, 107 (2000).

45. N. C. Maiti, S. Mazumdar, and N. Periasamy, J. Phys. Chem. B, 102, 1528 (1998). 